\title{
El concepto de tranquilidad establecido en la ley 1801 de 2016 en la tenencia de mascotas de compañía y de producción
}

\author{
The concept of tranquility established in law 1801 of 2016 in the possession of \\ companion and production pets
}

\author{
David Stiven Serna Palacio ${ }^{1}$ - Jennifer Valencia Ramírez ${ }^{2}$
}

\section{Resumen}

La tenencia responsable de animales implica el hecho de que quien se denomina propietario o tenedor de un animal asuma la responsabilidad de garantizarle sus necesidades básicas pero también mantenga en equilibrio la tranquilidad de quienes son sus vecinos y no avalan la idea de compartir con animales que por la producción de plagas, por sus olores o el ruido que ocasionan puedan ser afectados en sus derechos, lo que no está tipificado actualmente en la normatividad colombiana siendo un caso común sin solución legal alguna más que el intento de una conciliación por parte de los uniformados y/o el inspector de policía, es por ello que se busca establecer una solución eficaz exigible desde la normatividad vigente o generar la creación de un nuevo articulado que desde el derecho comparado se pueda adoptar y aplicar correctamente en un país donde los conflictos vecinales por la tenencia de mascotas son una realidad diaria.

Palabras clave: Convivencia, tenencia, tranquilidad, mascotas.

\begin{abstract}
The responsible ownership of animals implies the fact that whoever is called the owner or holder of an animal assumes the responsibility of guaranteeing their basic needs but also maintains in balance the tranquility of those who are their neighbors and do not endorse the idea of sharing with animals that for Their odors or the noise they cause may be affected by their rights, which is not currently typified in Colombian regulations, being a common case with no legal solution other than the attempt at conciliation by the uniformed officers and / or the inspector of police, that is why it seeks to establish an effective solution enforceable from the current regulations or generate the creation of a new article that from comparative law can be adopted and applied correctly in a country where neighborhood conflicts over pet ownership are a problem. daily reality.
\end{abstract}

Key Words: Coexistence, tenure, tranquility, pets.

\footnotetext{
${ }^{1}$ Abogado. Corporación Universitaria Americana. Correspondencia: Urrao, calle 42 № 26-67 código postal: 056830. sernadavid9825@americana.edu.co

${ }^{2}$ Abogada. Corporación Universitaria Americana. Correspondencia: Bello, Antioquia carrera 63 № 61-01 código posta 051054. valenciajennifer1896@americana.edu.co
} 


\section{Introducción}

En lo relacionado a la convivencia de personas con animales, establecido en la ley 1801 de 2016 es ineficiente cuando se trata de proteger un derecho como el de la tranquilidad, el cual a pesar de estar en el artículo 33 de la norma citada, actualmente es una incógnita el proceso de policía aplicable a los conflictos de convivencia relacionados con la tenencia de mascotas o animales de producción que afecten el derecho a la tranquilidad, cuando esta se ve afectada por la convivencia con animales que sin ser dañinos o deambular en el espacio público llegan a alterar el sosiego de la vecindad con su actuar en ocasiones con el ruido, la producción de moscas o malos olores, a sabiendas de que en lo concerniente a daños tácitos el cobro de los perjuicios se deberá hacer por la jurisdicción civiles necesario entonces identificar las acciones policivas aplicables a los casos relacionados con la tenencia de mascotas y animales domésticos, para así salvaguardar los derechos de los convivientes, pero antes definiendo el alcance de los conceptos de tranquilidad y seguridad a través del código de convivencia, haciendo la distinción entre animales bravíos, domésticos y domesticados mediante el estudio del código civil y la normatividad vigente y las políticas públicas para su tenencia.

\section{Materiales y métodos}

A través de un método de investigación deductivo se ahonda en la normatividad colombiana referente a las relaciones entre las personas y los animales en busca de especificar un procedimiento aplicable para casos donde la convivencia se vea afectada por la tenencia de mascotas o animales domésticos, específicamente donde se irrumpa en la tranquilidad de los vecinos y la comunidad.

Las incógnitas de esta investigación surgen en el municipio de Urrao - Antioquia donde es común convivir en la zona urbana con vecinos que en su patio tienen su galpón de gallinas, gallos de pelea, sus porquerizas, incluso algunos tienen pesebreras para sus caballos y en casos más comunes tienen cantidad de mascotas, perros y gatos regularmente. Lo que para las autoridades de policía es un inconveniente cuando se trata de solucionar problemas donde se ven involucrados dichos animales.

Es por ello que al tratarse de establecer un método policivo eficaz para darle una solución pronta a los inconvenientes vecinales por la tenencia de mascotas o animales domésticos, lo que se hace inicialmente es una búsqueda selectiva de la jurisprudencia y normatividad colombiana que se relacione directamente con la convivencia de personas y animales delimitando los procedimientos aplicables cuando por este compartir se perturbe la tranquilidad de quienes no tienen empatía con los seres sintientes o realmente se vean afectados por la cercanía a sus vecinos y sus mascotas.

\section{Desarrollo}

Durante algún tiempo laboré en el municipio de Urrao del departamento de Antioquia, fungiendo como asesor en la inspección de policía y llevando a cabo diferentes procedimientos que enmarcados en un proceso único de policía no satisfacían por completo una de las bases de la convivencia como lo es la tranquilidad, según el artículo 6 de la ley 1801 de 2016, esto con fundamento en los problemas presentados en dicho municipio, toda vez que todavía es una costumbre convivir en casas ubicadas en la zona urbana del municipio con caballos, cerdos, gallinas, gallos de pelea, y con sobrepoblación de mascotas, etc. Animales que normalmente producen un alza en la cantidad de moscas, de malos olores, e incluso hacen ruidos que a la par con las mascotas, irrumpen en el sosiego de los vecinos quienes en muchas ocasiones buscan un amparo en las autoridades de policía, 
Ya entrando en el tema de estudio, es necesario hacer la diferenciación de los tipos de animales para así, de existir normas específicas con uno u otro, poder tener la claridad de los casos en los que pueden aplicarse. Inicialmente el código civil en su artículo 687 los clasifica en 3 grupos:

"ARTICULO 687. <ANIMALES BRAVIOS, DOMESTICOS Y DOMESTICADOS>. Se Ilaman animales bravíos o salvajes los que viven naturalmente libres e independientes del hombre, como las fieras y los peces; domésticos, los que pertenecen a especies que viven ordinariamente bajo la dependencia del hombre, como las gallinas, las ovejas, y domesticados los que, sin embargo, de ser bravíos por su naturaleza, se han acostumbrado a la domesticidad, y reconocen en cierto modo el imperio del hombre.

Estos últimos, mientras conservan la costumbre de volver al amparo o dependencia del hombre, siguen la regla de los animales domésticos, y perdiendo esta costumbre vuelven a la clase de los animales bravíos."

Por su parte la ley 1801 de 2016, en lo relacionado con la tenencia de animales establece conductas sancionables como:

"Artículo 124. Comportamientos que ponen en riesgo la convivencia por la tenencia de animales. Los siguientes comportamientos ponen en riesgo la convivencia por la tenencia de animales y por lo tanto no deben efectuarse:

1. Dejar deambular semoviente, animales feroces o dañinos, en espacio público y privado, lugar abierto al público, o medio de transporte público, sin las debidas medidas de seguridad.

2. Impedir el ingreso o permanencia de perros lazarillos que, como guías, acompañen a su propietario o tenedor, en lugares públicos, abiertos al público, sistemas de transporte masivo, colectivo o individual o en edificaciones públicas o privadas.

3. Omitir la recogida de los excrementos de los animales, por parte de sus tenedores o propietarios, o dejarlos abandonados después de recogidos, cuando ello ocurra en el espacio público o en áreas comunes.

4. Trasladar un canino de raza potencialmente peligrosa en el espacio público, zonas comunes o en los lugares abiertos al público o en el transporte público en que sea permitida su estancia, sin bozal, trailla o demás implementos establecidos por las normas vigentes.

5. Incumplir las disposiciones para el albergue de animales.

6. Incumplir la normatividad vigente de importación, registro, posesión, compra, venta, traspaso, donación o cualquier cesión del derecho de propiedad sobre animal clasificado como potencialmente peligroso en la ley.

7. Tolerar, permitir o inducir por acción u omisión el que un animal ataque a una persona, a un animal o a bienes de terceros.

8. Entrenar ejemplares caninos para su participación en peleas como espectáculo, para la agresión de las personas, a las cosas $u$ otros animales o establecer asociaciones caninas orientadas para este fin.

9. Permitir que animales o mascotas esparzan, parcial o totalmente, en el espacio público o zonas comunes, el contenido de las bolsas y recipientes para la basura, una vez puestas para su recolección"

Las cuales se ligan con algunos artículos de la misma ley que a pesar de no hablar directamente sobre la tenencia de animales, se relacionan con los perjuicios que causa esta actividad en algunas ocasiones, uno de ellos es el numeral 7 del artículo 94, que establece

"Artículo 94. Comportamientos relacionados con la salud pública que afectan la actividad económica. Los siguientes comportamientos relacionados con la salud pública afectan la actividad económica y por lo tanto no deben realizarse:

7. No retirar frecuentemente los residuos de las áreas de producción o depósito y no evacuarlas de manera que se elimine la generación de malos olores, y se impida el refugio y alimen- 
Frente a éste, se puede decir que aborda temas importantes como la generación de malos olores y el hecho de laborar sin que por la higiene se evite el refugio y alimento de animales y plagas, pero para el caso que nos ocupa, al tratarse de buscar una norma similar que acoja a la comunidad en general y no sólo a quienes se les vea afectada la actividad económica no es posible, al menos en el código de policía y convivencia, determinar ese procedimiento preciso. Así mismo, otros artículos establecen conductas sancionables similares pero que al intentar ligarse con la tenencia de animales no se logra un avance significativo más que cuando se dé un caso específico de manera excepcional como, por ejemplo, el numeral 2 del artículo 102, que determina los comportamientos que afectan el aire así:

"Artículo 102. Comportamientos que afectan el aire. Los siguientes comportamientos afectan el aire y por lo tanto no se deben efectuar:

2. Emitir contaminantes a la atmósfera que afecten la convivencia."

A pesar de no mencionar animales es de mucha importancia invocar el apartado "que afecten la convivencia" pues es ahí donde se empiezan a plasmar los derechos de los vecinos afectados, entre ellos, a la tranquilidad.

Un concepto de derecho a la tranquilidad lo encontramos en la sentencia T-459/98, "Es el derecho a la tranquilidad, inherente a la persona humana, que le permite al individuo desarrollar una vida digna y sosegada. El derecho a la tranquilidad, lo ha dicho esta Sala, asume el carácter de fundamental por su estrecha relación con la dignidad humana que, necesariamente, conlleva a la paz individual la cual es necesaria para vivir adecuadamente. Como derecho inherente a la persona, el derecho a la tranquilidad debe ser protegido por el Estado de tal forma que permita un ambiente propicio para la convivencia humana, de manera que los individuos puedan realizar sus actividades en un ambiente sano y exento de cualquier molestia que tienda a vulnerar la paz y el sosiego"

En la ley 1801 de 2016 lo establecen como una categoría jurídica con la intención de lograr que los particulares ejerzan sus derechos y libertades sin abusar de los mismos, esto es, manteniendo cuidado sobre los derechos ajenos. Posteriormente se le da protección mediante el artículo 33 que establece:

"Artículo 33. Comportamientos que afectan la tranquilidad y relaciones respetuosas de las personas. Corregido por el art. 2, Decreto Nacional 555 de 2017. <El nuevo texto es el siguiente> Los siguientes comportamientos afectan la tranquilidad y relaciones respetuosas de las personas y por lo tanto no deben efectuarse:

1. En el vecindario o lugar de habitación urbana o rural: Perturbar o permitir que se afecte el sosiego con:

a) Sonidos o ruidos en actividades, fiestas, reuniones o eventos similares que afecten la convivencia del vecindario, cuando generen molestia por su impacto auditivo, en cuyo caso podrán las autoridades de Policía desactivar temporalmente la fuente del ruido, en caso de que el residente se niegue a desactivarlo;

b) Cualquier medio de producción de sonidos o dispositivos o accesorios o maquinaria que produzcan ruidos, desde bienes muebles o inmuebles, en cuyo caso podrán las autoridades identificar, registrar y desactivar temporalmente la fuente del ruido, salvo sean originados en construcciones o reparaciones en horas permitidas;

NOTA: Declarado exequible (el literal a) del numeral 1 del artículo 33 de la Ley 1801 de 2016, (la frase " desactivar temporalmente la fuente de ruido " contenida en el literal b) del numeral 1 del artículo 33. Sentencia C-308 de 2019. Magistrada Ponente: Diana Fajardo Rivera.

c) Actividades diferentes a las aquí señaladas en vía pública o en privado, cuando trascienda a lo público, y perturben o afecten la tranquilidad de las personas..." 
En ese orden de ideas se puede confirmar que desde el código de seguridad y convivencia ciudadana no se establece un procedimiento directo aplicable a las perturbaciones que se puedan presentar por la tenencia de mascotas o animales domésticos, específicamente donde se irrumpa en la tranquilidad de los vecinos y la comunidad, pero si garantiza una protección en casos específicos, ya determinados en los artículos 33, en cuanto al sonido donde determinan que con alguna actividad se altere el sosiego y trascienda a lo público, 94, cuando en actividades económicas se generen malos olores y se produzcan plagas, 102 , establece el caso de que se emitan contaminantes en el aire y con esto se afecte la convivencia y el 124 que determina conductas sancionables de los propietarios cuando de manera directa ponen en riesgo la convivencia por tener animales sin abordar esos daños que ocasionan de manera indirecta.

También es necesario tener claro lo que es la TENENCIA RESPONSABLE DE MASCOTAS, es definida por varios actores e instituciones de muchas maneras, pero al final la mayoría coinciden en una definición; el Conjunto de obligaciones que contrae una persona cuando decide aceptar y mantener una mascota o animal de compañía y que consisten, entre otras, en proporcionarle alimento, albergue y buen trato, brindarle los cuidados indispensables para su debido bienestar y no someterlo a sufrimientos evitables; definición que no difiere a lo que determina la Organización Mundial de Sanidad Animal como Propiedad Responsable de un Perro: "Designa la situación en que una persona acepta y se compromete a cumplir una serie de obligaciones dimanantes de la legislación vigente, encaminadas a satisfacer las necesidades comportamentales, ambientales y físicas de un perro y a prevenir los riesgos que este pueda presentar para la comunidad, para otros animales o para el medio".

De otra parte el Plan Decenal de Salud Púbica 2012 - 2021, define como una de las metas de la Dimensión de Salud Ambiental, "A 2021 el 100\% de las entidades territoriales se implementan la tenencia responsable de animales de compañía y de producción"; actividad que se debe adelantar en coordinación según competencias con Ministerio de Defensa Nacional; Ministerio de Justicia y del Derecho; Ministerio de Interior; Ministerio de Ambiente y Desarrollo Sostenible; Ministerio de Vivienda, Ciudad y Territorio; Ministerio de Agricultura y Desarrollo Rural, Ministerio de Educación Nacional; Ministerio de Transporte; Ministerio de Trabajo; Instituto Nacional de Salud; Departamento Nacional de Planeación; Entidades Territoriales, CAR y Autoridades Ambientales Urbanas, gobiernos departamentales, distritales y municipales.

La necesidad de contar en Colombia, con una Política Pública de Tenencia Responsable de Animales de Compañía y de Producción en el sentido más amplio de la palabra y dirigida absolutamente a todas las especies animales, es totalmente necesaria, así mismo la implementación de normas para esa tenencia y sanciones para quienes en su calidad de propietarios o tenedores perturben derechos de quienes por cercanía sean afectados por la convivencia con estos seres.

El marco legal colombiano es muy amplio en normas, pero no existe normatividad en materia de Tenencia Responsable de Animales de Compañía y sanciones para quienes los tengan en situaciones precarias y eso trascienda a lo público.

A continuación, se relacionan las normas más relevantes que tratan en su contenido temas alusivos a los animales:

Ley 1801 de 2016, "Por la cual se expide el Código Nacional de Policía y Convivencia".

Ley 1774 de 2016, “Por medio de la cual se modifican el Código Civil, La Ley 84 de 1989, El Código Penal, El Código de Procedimiento Penal y se dictan otras disposiciones".

Ley 84 de 1989, “Por la cual se adopta el Estatuto Nacional de Protección de los Anima- 
les y se crean unas contravenciones y se regula lo referente a su procedimiento y competencia".

Ley 769 de 2002, “Por la cual se expide el Código Nacional de Tránsito Terrestre y se dictan otras disposiciones".

Decreto 780 de 2016, “Por medio del cual se expide el Decreto Único Reglamentario del Sector Salud y Protección Social".

Plan Decenal de Salud Pública 2012 - 2021

No se puede desconocer la normatividad de los sectores salud, agropecuario, ambiente, educación, gobierno, defensa, justicia, vivienda, porque si bien establecen competencias puntuales de su sector, de manera inmersa abordan la problemática de la Tenencia Responsable de Animales de Compañía y de Producción, como un deber del estado colombiano.

Ahora bien, frente al caso que nos ocupa, se ha encontrado normatividad a nivel departamental, específicamente para el caso de Antioquia donde actualmente a pesar de existir el código de policía sigue vigente y establece pautas para la tenencia y convivencia con animales, dedicando así un capítulo completo a los animales domésticos y otro a caninos y mascotas, donde establece:

“...Articulo 145. A quien tenga cocheras, pesebreras, establos o similares en estado de notorio desaseo, se le ordenará por el Alcalde o Inspector de Policía, su limpieza inmediata, si incumple lo ordenado será sancionado con multa de medio (1/2) a tres (3) salarios mínimos legales mensuales vigentes, sin perjuicio de las demás acciones a que haya lugar de conformidad con lo ordenado con la Ley 9a de 1979 a cargo de las autoridades sanitarias. Parágrafo: Queda prohibida la ubicación de cocheras o porquerizas, como actividad comercial con un número superior a tres (3) cerdos, dedicados a la cría, mantenimiento o engorde, dentro de la zona urbana de los municipios o corregimientos..."

En el apartado sobre caninos y mascotas es importante destacar lo referido a la tranquilidad de los vecinos, tal derecho es protegido en el artículo 48, que invoca:

"Artículo 148. Los responsables o propietarios de caninos, animales domésticos y mascotas están obligados a adoptar las medidas necesarias para impedir que la tranquilidad de sus vecinos se vea alterada por su comportamiento El desconocimiento de lo anterior será sancionado con multa de uno (1) a diez (10) salarios mínimos legales diarios vigentes."

Así pues, en el departamento de Antioquia se da una garantía de tranquilidad a los vecinos de quienes son poseedores de animales domésticos, pero ¿qué tan procedente es dicha sanción cuando se entiende que con la salida del código de policía dicha norma pudo haber sido derogada? Y en realidad hay algunas situaciones en que no se legisla desde la ley 1801 de 2016 y esos vacíos pueden ser encontrados en la ordenanza 018 de 2002, es por ello que a nivel nacional se hace todavía necesario legislar sobre un medio eficaz para proteger ese derecho ala tranquilidad desde el código de seguridad y convivencia ciudadana, específicamente en situaciones donde se vea afectada por aquellos animales domésticos.

\section{Conclusiones}

Los Alcaldes Municipales y Distritales, como máxima autoridad en su jurisdicción, deben liderar la formulación e implementación de las estrategias e intervenciones que propendan por el bienestar de los animales y la tranquilidad de los vecinos.

Es acertado pensar que una de las principales causas de las cuales motivaron hacer 
este estudio es la falta de un procedimiento claro para dar solución pronta y oportuna en los casos en que se ve afectada la convivencia por la tenencia de animales domésticos sean mascotas o animales de producción, esto en relación con el derecho a la tranquilidad amparado por la ley 1801 de 2016, por ello, al no encontrar desde la misma ley dicho procedimiento, la conclusión más evidente es que no se puede determinar ese amparo policivo eficaz hasta tanto no se vincule a procedimientos específicos como los expresados en el desarrollo de este escrito, entre ellos los enunciados en los artículos 33, 94, 102 y 124.

Se debe implementar de manera urgente una Política Pública de tenencia Responsable de Animales, mascotas y demás, para definir de manera puntual, la competencia de estos actores y sectores público - privados, deberes y derechos de los animales, restricciones de tenencia, sanciones para cuando estos irrumpan en la tranquilidad de los vecinos, y demás regulación y fiscalización en la materia a nivel nacional.

Los Alcaldes Municipales y Distritales, como máxima autoridad en su jurisdicción, además, con las facultades que les otorga el código de seguridad y convivencia, deben liderar la formulación e implementación de las estrategias e intervenciones que propendan por el bienestar de los animales y la tranquilidad de los vecinos.

\section{Bibliografía}

Ley 1801 de 2016, “Por la cual se expide el Código Nacional de Policía y Convivencia.

Ordenanza 018 de 2002 “Por la cual se expide el Código De Convivencia Ciudadana para el Departamento de Antioquia"

LEY 84 DE 1873 “Código Civil” 